\title{
Glucose metabolism before and after radioiodine therapy of a patient with Graves' disease: Assessment by continuous glucose monitoring
}

\author{
YUN HU, GU GAO, RENG-NA YAN, FENG-FEI LI, XIAO-FEI SU and JIAN-HUA MA \\ Department of Endocrinology, Nanjing First Hospital, Nanjing Medical University, Nanjing, Jiangsu 210012, P.R. China
}

Received March 17, 2017; Accepted June 7, 2017

DOI: $10.3892 /$ br.2017.932

\begin{abstract}
Hyperthyroidism causes impaired glucose tolerance, insulin resistance (IR) and insulin secretion. However, the glucose variability affected by thyroid dysfunction remains unclear. Glucose variability was assessed by continuous glucose monitoring (CGM) in a non-diabetic patient with Graves' disease (GD), to the best of our knowledge, for the first time. A 28-year-old man with GD, who had been taking methimazole for 4 years, was treated with radioiodine on August 17th 2016. Although the patient exhibited normal glycated hemoglobin (HbA1c; 5.3\%) and blood glucose values during the oral glucose tolerance test (OGTT; fasting and $120 \mathrm{~min}$ blood glucose were 5.38 and $6.39 \mathrm{mmol} / 1$, respectively) before radioiodine therapy, CGM exhibited high $24 \mathrm{~h}$ mean glucose and nocturnal hyperglycemia. An increased fasting insulin level, suppressed levels of blood glucagon and high homeostatic model assessment of IR were also observed. The disordered glucose metabolism improved as soon as the patient's thyroid function turned to hypothyroidism 4 months after radioiodine therapy. The glucose intolerance in patients with hyperthyroidism, missed by the OGTT and HbAlc tests, may be more common than anticipated.
\end{abstract}

\section{Introduction}

Impaired glucose tolerance, insulin resistance (IR) and insulin secretion have been observed in hyperthyroidism and hypothyroidism (1-6). Known factors responsible for abnormal glucose tolerance include aberrant metabolic rate, endogenous gluconeogenesis and glucose absorption, which are affected by thyroid hormone $(7,8)$.

The American Diabetic Association has recently approved the use of glycated hemoglobin (HbA1c) as a screening method,

Correspondence to: Dr Jian-Hua Ma, Department of Endocrinology, Nanjing First Hospital, Nanjing Medical University, 32 Gongqingtuan Road, Nanjing, Jiangsu 210012, P.R. China

E-mail: majianhua196503@126.com

Key words: hyperthyroidism, glucose metabolism, radioiodine therapy, continuous glucose monitoring as well as a diagnostic test for diabetes mellitus. However, previous studies identified that HbAlc is not a reliable diagnostic test for diabetes in the presence of hyperthyroidism or hypothyroidism $(9,10)$.

The prevalent use of continuous glucose monitoring (CGM) has provided details on glycemic variation that were otherwise not possible with HbAlc or self-monitoring of blood glucose (SMBG). Torimoto et al (11) reported the use of CGM in a patient with Graves' disease (GD) complicated by diabetes mellitus. The authors demonstrated that hyperthyroidism induces elevation of postprandial blood glucose (PBG) and fasting blood glucose (FBG) levels due to the dawn phenomenon, and that glycemic variation is alleviated with improvement in thyroid function. However, in the aforementioned case, the patient was diabetic and exogenous insulin was used, which may have interfered with the blood glucose levels.

Radioiodine therapy is one of the most popular treatment strategies for GD in China. The present study describes a patient with GD, who presented with hyperthyroidism and subsequently exhibited hypothyroidism following radioiodine therapy. CGM was employed to observe the glycemic variation during the hyperthyroidism and hypothyroidism states.

\section{Case report}

The patient was a 28-year-old man. He began to experience heart palpitations, tremors and weight loss in 2012, and was diagnosed with GD and treated with methiamazole. The patient persisted with the treatment for 4 years; however, the thyroid hormone levels did not return to normal (TSH 0.35-4.9 mIU/1 and FT4 9-19 pmol/l). Therefore, the patient chose radioiodine therapy and stopped the methiamazole treatment on August 2nd 2016. The dose of methiamazole was $15 \mathrm{mg}$ per day when the drug was withdrawn. There was no family history of thyroid disease. He admitted to Nanjing First Hospital on August 10th 2016. The signed informed consent of radioiodine therapy and including in the present study was obtained.

Prior to radioiodine therapy, the patient was $179.0 \mathrm{~cm}$ tall and weighed $71 \mathrm{~kg}$ [body mass index (BMI), $22.16 \mathrm{~kg} / \mathrm{m}^{2}$ ). The patient's blood pressure was $120 / 80 \mathrm{mmHg}$ and heart rate was $88 \mathrm{bpm}$ and he exhibited clear consciousness. Diffuse goiter was noted on clinical examination. The respiratory and heart 
Table I. Blood thyroid hormone levels.

\begin{tabular}{lcccccc}
\hline Hormone & $\begin{array}{c}\text { August 8th, } \\
2016\end{array}$ & $\begin{array}{c}\text { September 16th, } \\
2016\end{array}$ & $\begin{array}{c}\text { October 19th, } \\
2016\end{array}$ & $\begin{array}{c}\text { December 16th, } \\
2016\end{array}$ & $\begin{array}{c}\text { January 20th, } \\
2017\end{array}$ & $\begin{array}{c}\text { Normal } \\
\text { range }\end{array}$ \\
\hline TSH (mIU/l) & $<0.007$ & $<0.007$ & $<0.007$ & 82.42 & 37.27 & $0.35-4.94$ \\
FT3 (pmol/l) & $>46.08$ & 10.96 & 7.33 & 3.26 & 4.03 & $2.63-5.70$ \\
FT4 (pmol/l) & 38.36 & 27.55 & 23.79 & 5.15 & 10.67 & $9.00-19.00$ \\
\hline
\end{tabular}

The patient missed a visit in November. TSH, thyroid stimulating hormone; FT3, free triiodothyronine; FT4, free thyroxine.

sounds were normal, and the neurological examination was normal.

Prior to radioiodine therapy, laboratory tests exhibited normal hepatic and renal functions, as well as standard normal serum electrolytes. Thyrotrophin receptor antibody was $6.38 \mathrm{IU} / 1$ (normal range, $<1.75 \mathrm{IU} / \mathrm{l}$ ). Thyroid uptake rates were $95.7 \%$ at $2 \mathrm{~h}, 97.1 \%$ at $6 \mathrm{~h}$ and $95.4 \%$ at $24 \mathrm{~h}$. The Tc-99m scan indicated an enlarged thyroid and increased uptake rate.

Oral glucose tolerance tests (OGTTs) using $75 \mathrm{~g}$ glucose (dissolved in $200 \mathrm{ml}$ water) were performed prior to radioiodine therapy. Serum samples were obtained before, and 30 and 120 min after oral administration of blood glucose, insulin, C-peptide and glucagon determination. The ratio of glucagon/glucose (GLA/GLU) and GLA/insulin (INS) were calculated to represent the inhibition of glucose or insulin on glucagon secretion.

The patient was subjected to 3-day retrospective CGM (Sof-sensor; CGMS-Gold, Medtronic Incorporated, Northridge, LA, USA) in the presence of hyperthyroidism and hypothyroidism. During the CGM period, the patient was instructed to maintain his usual physical activity and received meals consisting of total caloric intake of $25 \mathrm{kcal} / \mathrm{kg} / \mathrm{day}$. The ratio of carbohydrate, protein and fats was $\sim 55,17$ and $28 \%$, respectively. The CGM was corrected 4 times per day by SMBG.

The patient was administered 13 m Ciradioactive iodine $\left({ }^{131} \mathrm{I}\right)$ on August 17th 2016. Thyroid function tests were repeated every month after radioiodine therapy (Table I) and OGTT was performed again when the thyroid hormone exhibited hypothyroidism on December 23rd 2016, while blood lipid measurements and CGM were also performed.

OGTTs demonstrated increased blood insulin and C-peptide levels 30 min after oral glucose administration in the hypothyroidism state compared with in the hyperthyroidism state, while the blood glucose levels, and fasting and 120 min-insulin exhibited little change (Fig. 1A). The blood glucagon level was suppressed when the patient exhibited hyperthyroidism, and the glucagon secretion was improved following radioiodine therapy (Fig. 1B). The insulin area under the curve (AUC) was higher in the hyperthyroidism state than in the hypothyroidism state (Fig. 1C). HbA1c decreased $0.2 \%$ following radioiodine therapy. Although homeostatic model assessment of IR (HOMA-IR) before and after radioiodine therapy was higher than normal, the HOMA-IR decreased following radioiodine therapy (Fig. 1C). Total cholesterol, triglyceride, low-density lipoprotein cholesterol (LDL-c) and high density lipoprotein cholesterol aberrantly increased when the patient entered the hypothyroidism state (Fig. 2).

CGM was performed to assess glucose variability on August 11th 2016 and December 23rd 2016 for 3 days. The patient exhibited a reduction in 24-h mean glucose (MG) following radioiodine therapy. No significant differences in the standard deviation of the $\mathrm{MG}\left(\mathrm{SD}_{\mathrm{MG}}\right)$ and the 24-h mean amplitude of glycemic excursion (MAGE) between the hypothyroidism and hyperthyroidism states (Table II). Prior to radioiodine therapy, nocturnal hyperglycemia was observed by CGM occurring at 8:00 p.m. when the patient fell asleep, and the blood glucose was maintained at a high level until before breakfast (7:00 a.m.; Fig. 3A). Nocturnal blood glucose, which was demonstrated by the AUC for glucose during the night (8:00 p.m.-7:00 a.m.; $\mathrm{AUC}_{\text {night }}$ ), improved when the patient exhibited hypothyroidism following radioiodine therapy (Table II). The dawn phenomenon (from 4:00 to 7:00 a.m.) was also observed prior to radioiodine therapy (Fig. 3A). The relative contributions of FBG and PBG to 24-h hyperglycemia were calculated as described in a previous study (12). Glucose AUC above a glucose value of $5.6 \mathrm{mmol} / \mathrm{l}$ in $24 \mathrm{~h}$ was defined as $\mathrm{AUC}_{\text {total }}$ to represent overall hyperglycemia. The area above $\mathrm{FBG}$ $\left(\mathrm{AUC}_{\mathrm{PPG}}\right)$ was defined as the contribution of PBG to overall hyperglycemia over $24 \mathrm{~h}$. The proportion of the contributions of FBG and $\mathrm{PBG}$ to $24 \mathrm{~h}$ hyperglycemia was calculated as

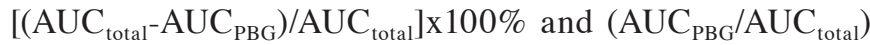
$\mathrm{x} 100 \%$, respectively. The $\mathrm{AUC}_{\text {total }}$ decreased and the contributions of FBG to $24 \mathrm{~h}$ hyperglycemia decreased from 48.9 to $25.8 \%$, along with a marked decrease in the thyroid hormone level (Fig. 3B).

The patient exhibited no significant symptoms of hypothyroidism following radioiodine therapy, although his weight had increased to $76.5 \mathrm{~kg}$ (BMI, $23.88 \mathrm{~kg} / \mathrm{m}^{2}$ ) by December 23rd 2016. Thereafter, the patient commenced sodium levothyroxine treatment $(50 \mu \mathrm{g} /$ day $)$. The levels of thyroid hormone (Table I) and blood lipids had returned to normal by January 20th 2017.

\section{Discussion}

To the best of our knowledge, this is the first study to describe the use of CGM to evaluate glucose variability in a non-diabetic patient with hyperthyroidism. Though the patient exhibited normal HbAlc and blood glucose levels in OGTT, his CGM data showed abnormity in glucose metabolism. The 24-h MG before radioiodine therapy was higher than the normal range for 

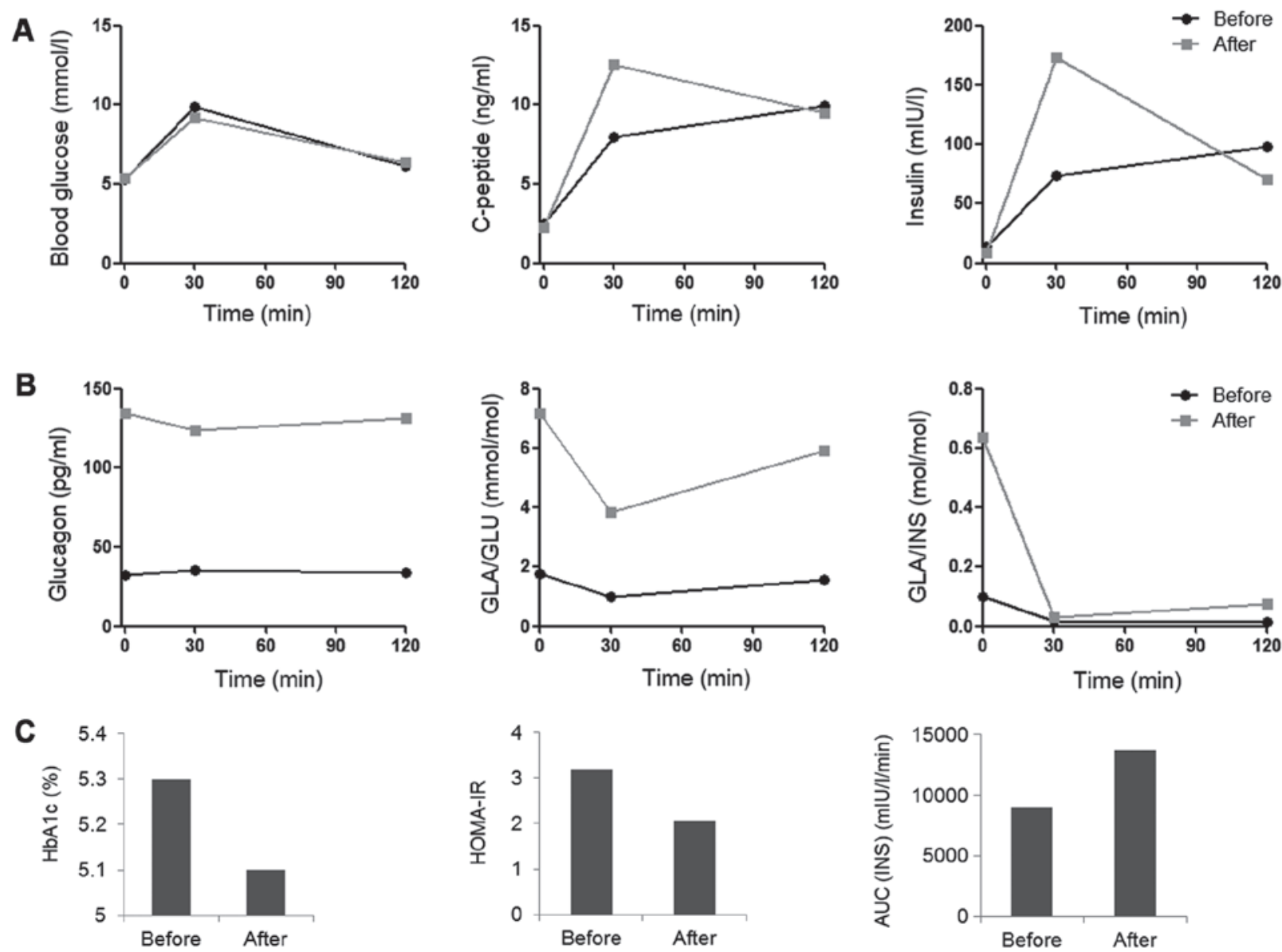

Figure 1. Glucose metabolism of a patient with Graves' disease before and after radioiodine therapy. (A) Blood glucose, insulin and C-peptide before, and 30 and 120 min after OGTT. (B) Blood glucagon levels and the inhibition of glucose and insulin on glucagon secretion (GLA/GLU and GLA/INS) in OGTT. (C) HbAlc, HOMA-IR and AUC (INS) before and after radioiodine therapy. OGTT, oral glucose tolerance test; HbAlc, glycated hemoglobin; GLA, glucagon; GLU, glucose; INS, insulin; HOMA-IR, homeostatic model assessment of insulin resistance; AUC (INS), insulin area under the curve.

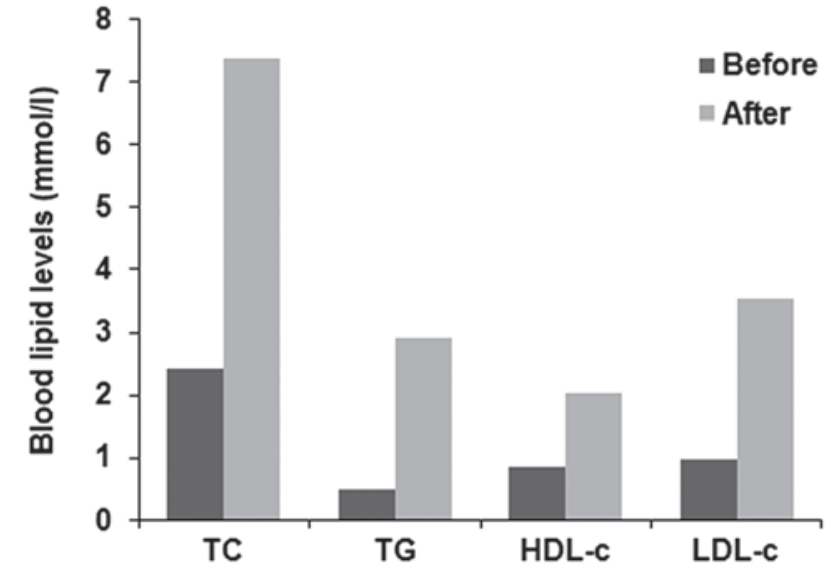

Figure 2. Blood lipid levels before and after radioiodine therapy. TC, total cholesterol; TG, triglyceride; LDL-c, low-density lipoprotein cholesterol; HDL-c, high-density lipoprotein cholesterol.

the Chinese population (13) and was higher than the 24-h MG (5.77 $\mathrm{mmol} / \mathrm{l}$ ) calculated by HbA1c using the following equation: 24-h MG (mmol/l)=1.198 x HbAlc-0.582 (14). Following radioiodine therapy, the 24-h MG fell to within the normal range, accompanied by decreased thyroid hormone, while the blood glucose in OGTT and the HbAlc value decreased slightly.
The current study demonstrated that the sensitivity of CGM in patients with hyperthyroidism was higher than that of HbAlc and OGTT. The reasons for low sensitivity of HbA1c in patients with thyroid dysfunction remain unclear. One reason may be the alteration of erythrocytes in circulation caused by thyroid dysfunction $(10,15)$. OGTT may not account for nocturnal hyperglycemia, which was observed in the present report. A previous study identified increased secretion of growth hormone in thyrotoxicosis (16), which may contribute to nocturnal hyperglycemia. Klieverik et al (17) identified that following local application of T3 to thyroid hormone sensitive neurons in the paraventricular nucleus, an increased sympathetic outflow to the liver significantly stimulated hepatic gluconeogenesis. Nocturnal hyperglycemia in hyperthyroid patients may also be caused by sympathetic overactivity. The relative contributions of FBG and PBG to 24-h hyperglycemia were similar in hyperthyroidism, although the contributions of FBG to 24-h hyperglycemia decrease markedly due to the improvement of nocturnal hyperglycemia following radioiodine therapy.

The patient in the present case exhibited high HOMA-IR, which was attributed to a high fasting insulin level. The result was similar to previous studies $(18,19)$. In addition, the HOMA-IR level decreased following radioiodine therapy accompanied by decreased fasting and 120-min insulin 
Table II. Parameters of glycemic variability measured by continuous glucose monitoring.

\begin{tabular}{|c|c|c|c|c|c|c|}
\hline \multirow[b]{2}{*}{ Variable } & \multicolumn{3}{|c|}{ Hyperthyroidism } & \multicolumn{3}{|c|}{ Hypothyroidism } \\
\hline & Day 1 & Day 1 & Day 3 & Day 1 & Day 1 & Day 3 \\
\hline MG (mmol/l) & 6.93 & 6.40 & 5.86 & 4.90 & 5.30 & 5.00 \\
\hline $\mathrm{AUC}_{\text {night }}(\mathrm{mmol} / \mathrm{l})$ & 3,552 & 3,371 & 3,583 & 2,718 & 3,440 & 2,911 \\
\hline $\mathrm{SD}_{\mathrm{MG}}(\mathrm{mmol} / \mathrm{l})$ & 0.81 & 0.42 & 0.96 & 0.65 & 0.62 & 0.64 \\
\hline MAGE (mmol/l) & 1.30 & 1.40 & 2.24 & 2.18 & 1.43 & 1.36 \\
\hline$\% \mathrm{CV}(\%)$ & 11.74 & 6.64 & 16.39 & 13.33 & 11.61 & 12.82 \\
\hline MODD (mmol/l) & 0.73 & 2.43 & 1.30 & 0.84 & & \\
\hline
\end{tabular}

MG, 24-h mean glucose; $\mathrm{AUC}_{\text {night }}$, area under the curve for glucose during the night; $\mathrm{SD}_{\mathrm{MG}}$, standard deviation of the MG; MAGE, 24-h mean amplitude of glycemic excursion; \% CV, the percentage coefficient of variation; MODD, mean of daily differences.
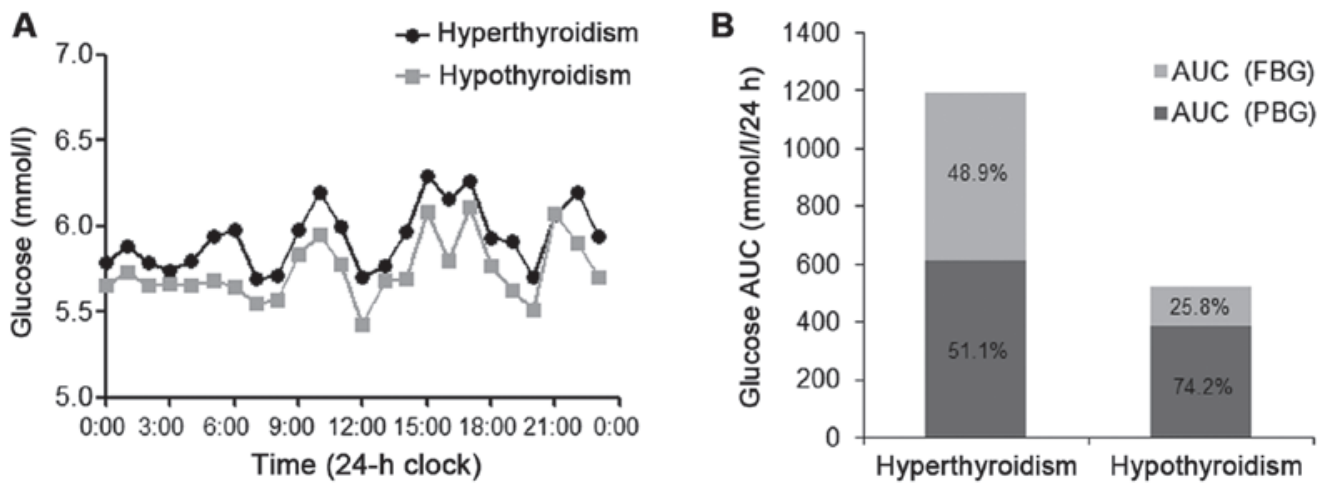

Figure 3. Continuous glucose monitoring analysis in the hyperthyroidism and hypothyroidism states. (A) The hourly mean blood glucose concentration over 3 days. (B) The relative contributions of FBG and PBG to $24 \mathrm{~h}$ hyperglycemia. Glucose AUC $>5.6 \mathrm{mmol} / \mathrm{l}$ in $24 \mathrm{~h}$ was defined as AUC $\mathrm{C}_{\text {total }}$ to represent overall hyperglycemia. The area above FBG [AUC(PBG)] was defined as the contribution of PBG to overall hyperglycemia over $24 \mathrm{~h} . \mathrm{AUC}(\mathrm{FBG})=\mathrm{AUC} \mathrm{total}^{-}[\mathrm{AUC}(\mathrm{PBG})]$. FBG, fasting blood glucose; PBG, postprandial blood glucose; AUC, area under the curve.

levels. However, the 30-min insulin level, which partially represented the first phase of insulin secretion, increased significantly.

The present case demonstrated low glucagon levels in thyrotoxicosis. The GLA/GLU and GLA/INS, which indicates the inhibition of glucose and insulin on glucagon, were also lower than after radioiodine therapy. Previous studies demonstrated conflicting data regarding plasma glucagon levels of patients with hyperthyroidism $(20,21)$. Hepatic glycogen depletion in hyperthyroidism may stimulate glucagon secretion and aggravate glucose intolerance $(22,23)$. However, high blood glucose and insulin levels inhibit glucagon secretion (20). Furthermore, the metabolic clearance rate of glucagon was significantly increased in hyperthyroidism (21) and may explain the phenomenon in the current report.

In this case MAGE and $\mathrm{SD}_{\mathrm{MG}}$ before and after radioiodine therapy were within the normal ranges (MAGE, $<3.9 \mathrm{mmol} / 1$ and $\left.\mathrm{SD}_{\mathrm{MG}},<1.4 \mathrm{mmol} / \mathrm{l}\right)(24)$ and were not significantly different. However, a previous study demonstrated that MAGE and $\mathrm{SD}_{\mathrm{MG}}$ were increased in patients with diabetes and hyperthyroidism, and could be improved when the thyroid function normalized (11). Further case-control studies are recommended for the glucose variability in patients with thyroid dysfunction.
A previous study showed that the early onset of hypothyroidism following radioiodine therapy in GD is particularly common (57\%) (25). Radioiodine therapy causes oxidative stress (26) and aggravates glucose intolerance. In the present case, glucose metabolism was improved following radioiodine therapy, but dyslipidemia was observed when the patient exhibited hypothyroidism. The blood lipid levels returned to normal following thyroid hormone replacement therapy without lipid-lowing therapy. Hence, close monitoring of blood lipids and thyroid function following radioiodine therapy is important.

In conclusion, to the best of our knowledge the current study is the first to identify high 24-h MG and nocturnal hyperglycemia using CGM in a non-diabetic patient with hyperthyroidism. Thus, glucose metabolism disorder in patients with hyperthyroidism, which is not identified by OGTT and HbAlc test, may be more common than previously believed.

\section{References}

1. Ahrén B: Hyperthyroidism and glucose intolerance. Acta Med Scand 220: 5-14, 1986.

2. Fukuchi M, Shimabukuro M, Shimajiri Y, Oshiro Y, Higa M, Akamine H, Komiya I and Takasu N: Evidence for a deficient pancreatic beta-cell response in a rat model of hyperthyroidism. Life Sci 71: 1059-1070, 2002. 
3. Karbalaei N, Noorafshan A and Hoshmandi E: Impaired glucose-stimulated insulin secretion and reduced $\beta$-cell mass in pancreatic islets of hyperthyroid rats. Exp Physiol 101: 1114-1127, 2016.

4. Ozdemir D, Dagdelen S and Usman A: Serum Adiponectin Levels and Changes in Glucose Metabolism before and after Treatment for Thyroid Dysfunction. Intern Med 54: 1849-1857, 2015.

5. Maratou E, Hadjidakis DJ, Peppa M, Alevizaki M, Tsegka K, Lambadiari V, Mitrou P, Boutati E, Kollias A, Economopoulos T, et al: Studies of insulin resistance in patients with clinical and subclinical hyperthyroidism. Eur J Endocrinol 163: 625-630, 2010.

6. Maratou E, Hadjidakis DJ, Kollias A, Tsegka K, Peppa M, Alevizaki M, Mitrou P, Lambadiari V, Boutati E, Nikzas D, et al: Studies of insulin resistance in patients with clinical and subclinical hypothyroidism. Eur J Endocrinol 160: 785-790, 2009.

7. Levin RJ and Smyth DH: The effect of the thyroid gland on intestinal absorption of hexoses. J Physiol 169: 755-769, 1963.

8. Dimitriadis GD and Raptis SA: Thyroid hormone excess and glucose intolerance. Exp Clin Endocrinol Diabetes 109 (Suppl 2) S225-S239, 2001.

9. Yang L, Shen X, Yan S, Yuan X, Lu J and Wei W: HbA1c in the diagnosis of diabetes and abnormal glucose tolerance in patients with Graves' hyperthyroidism. Diabetes Res Clin Pract 101: 28-34, 2013.

10. Anantarapu S, Vaikkakara S, Sachan A, Phaneendra BV, Suchitra MM, Reddy AP, Epuri S, Mukka A and Vemvakam D: Effects of thyroid hormone replacement on glycated hemoglobin levels in non diabetic subjects with overt hypothyroidism. Arch Endocrinol Metab 59: 495-500, 2015.

11. Torimoto K, Okada Y, Arao T, Mori H, Yamamoto S, Narisawa M, Kurozumi A and Tanaka Y: Glucose variability before and after treatment of a patient with Graves' disease complicated by diabetes mellitus: Assessment by continuous glucose monitoring. Endocr J 61: 321-328, 2014.

12. Wang JS, Tu ST, Lee IT, Lin SD, Lin SY, Su SL, Lee WJ and Sheu WH: Contribution of postprandial glucose to excess hyperglycaemia in Asian type 2 diabetic patients using continuous glucose monitoring. Diabetes Metab Res Rev 27: 79-84, 2011.

13. Zhou J, Li H, Ran X, Yang W, Li Q, Peng Y, Li Y, Gao X, Luan X, Wang W, et al: Reference values for continuous glucose monitoring in Chinese subjects. Diabetes Care 32: 1188-1193, 2009.

14. Zhou J, Mo Y, Li H, Ran X, Yang W, Li Q, Peng Y, Li Y, Gao X, Luan $\mathrm{X}$, et al: Relationship between HbAlc and continuous glucose monitoring in Chinese population: A multicenter study. PLoS One 8: e83827, 2013
15. Messarah M, Saoudi M, Boumendjel A, Boulakoud MS and Feki AE: Oxidative stress induced by thyroid dysfunction in rat erythrocytes and heart. Environ Toxicol Pharmacol 31: 33-41, 2011.

16. Iranmanesh A, Lizarralde G, Johnson ML and Veldhuis JD: Nature of altered growth hormone secretion in hyperthyroidism. J Clin Endocrinol Metab 72: 108-115, 1991.

17. Klieverik LP, Janssen SF, van Riel A, Foppen E, Bisschop PH, Serlie MJ, Boelen A, Ackermans MT, Sauerwein HP, Fliers E, et al: Thyroid hormone modulates glucose production via a sympathetic pathway from the hypothalamic paraventricular nucleus to the liver. Proc Natl Acad Sci USA 106: 5966-5971, 2009.

18. Al-Shoumer KA, Vasanthy BA and Al-Zaid MM: Effects of treatment of hyperthyroidism on glucose homeostasis, insulin secretion, and markers of bone turnover. Endocr Pract 12: 121-130, 2006.

19. Theodoropoulou A, Psyrogiannis A, Metallinos IC, Habeos I, Vgenakis AG and Kyriazopoulou V: Ghrelin response to oral glucose load in hyperthyroidism, before and after treatment with antithyroid drugs. J Endocrinol Invest 32: 94-97, 2009.

20. Tosi F, Moghetti P, Castello R, Negri C, Bonora E and Muggeo M: Early changes in plasma glucagon and growth hormone response to oral glucose in experimental hyperthyroidism. Metabolism 45: 1029-1033, 1996

21. Dimitriadis G, Hatziagelaki E, Mitrou P, Lambadiari V, Maratou E, Raptis AE, Gerich JE and Raptis SA: Effect of hyperthyroidism on clearance and secretion of glucagon in man. Exp Clin Endocrinol Diabetes 119: 214-217, 2011.

22. Kabadi UM: Is hepatic glycogen content a regulator of glucagon secretion? Metabolism 41: 113-115, 1992.

23. Aranda A, Montoya E and Herrera E: Effects of hypo- and hyper-thyroidism on liver composition, blood glucose, ketone bodies and insulin in the male rat. Biochem J 128: 597-604, 1972.

24. Zhou J, Li H, Ran X, Yang W, Li Q, Peng Y, Li Y, Gao X, Luan X, Wang W, et al: Establishment of normal reference ranges for glycemic variability in Chinese subjects using continuous glucose monitoring. Med Sci Monit 17: CR9-CR13, 2011.

25. Vijayakumar V, Ali S, Nishino T and Nusynowitz M: What influences early hypothyroidism after radioiodine treatment for Graves' hyperthyroidism? Clin Nucl Med 31: 688-689, 2006.

26. Rosário PW, Batista KC and Calsolari MR: Radioiodine-induced oxidative stress in patients with differentiated thyroid carcinoma and effect of supplementation with vitamins $C$ and $E$ and selenium (antioxidants). Arch Endocrinol Metab 60: 328-332, 2016. 